\title{
Pengaruh Dosis Limbah Cair dan Abu Boiler Pabrik Kelapa Sawit terhadap Pertumbuhan Bibit Kelapa Sawit (Elaeis guineensis jacq.) di Pre Nursery
}

\section{Effect of Palm Oil Mill Liquid Waste Dose and Boiler Ash on Growth of Oil Palm Seedlings (Elaeis guineensis jacq.) In Pre Nursery}

\author{
Ade Dinas, Dadi Nurdiana, Hany Hidayati Nafi'ah \\ Program Studi Agroteknologi, Fakultas Pertanian, Universitas Garut, \\ Jl. Raya Samarang No.52A, Tarogong Kaler, Kabupaten Garut, Jawa Barat 44151 \\ e-mail : hanny.hidayati@uniga.ac.id
}

\begin{abstract}
ABSTRAK
Penelitian ini bertujuan untuk mengetahui pengaruh dosis limbah cair dan abu boiler pabrik kelapa sawit manakah yang memberikan nilai tertinggi terhadap pertumbuhan bibit kelapa sawit di pre nursery. Penelitian dilaksanakan di Kampung Sukaraja Desa Jatisari Kecamatan Karangpawitan Kabupaten Garut, dengan ketinggian tempat 715 mdpl dan dilaksanakan pada Bulan September Desember 2019. Metode yang digunakan dalam penelitian adalah eksperimental dengan menggunakan Rancangan Acak Kelompok (RAK) pola Faktorial 4 x 4 diulang dua kali. Faktor perlakuan pertama adalah Dosis Limbah Cair Pabrik Kelapa Sawit $(\mathrm{P})$ dengan empat taraf, yaitu : $\mathrm{p}_{0}=$ Kontrol, $\mathrm{p}_{1}=2000 \mathrm{ml} /$ tanaman, $\mathrm{p}_{2}=3000 \mathrm{ml} /$ tanaman, dan $\mathrm{p}_{3}=4000 \mathrm{ml} /$ tanaman. Faktor perlakuan kedua adalah Dosis Abu Boiler Pabrik Kelapa sawit $(\mathrm{K})$ dengan empat taraf yaitu : $\mathrm{k}_{0}=$ Kontrol, $\mathrm{k}_{1}=10 \mathrm{~g} /$ tanaman, $\mathrm{k}_{2}=20 \mathrm{~g} /$ tanaman, dan $\mathrm{k}_{3}=30 \mathrm{~g} /$ tanaman. Hasil penelitian menunujukkan tidak terjadi interaksi antara berbagai dosis limbah cair dan abu boiler pabrik kelapa sawit terhadap pertumbuhan bibit kelapa sawit. Pengaruh mandiri dosis limbah cair pabrik kelapa sawit $4000 \mathrm{ml} /$ tanaman dapat memberikan rata-rata tertinggi pada parameter pengamatan luas daun dan bobot kering tajuk. Perlakuan dosis abu boiler kelapa sawit 30 gram/tanaman memberikan pengaruh yang berbeda nyata pada tinggi tanaman umur 90 HST, luas daun, bobot kering tajuk.
\end{abstract}

Kata kunci : abu boiler, kelapa sawit, limbah cair, pabrik kelapa sawit.

\section{ABSTRACT}

This study aims to determine the effect of the dose of liquid waste and ash of the palm oil mill boiler which gives the highest value to the growth of oil palm 
seedlings in pre nursery. The experiment was carried out in Sukaraja Village, Jatisari Village, Karangpawitan District, Garut Regency, with a height of 715 meters above sea level and carried out in September - December 2019. The method used in the study was experimental using a Randomized Block Design (RBD) Factorial pattern $4 \times 4$ repeated twice. The first treatment factor was the Palm Oil Mill Liquid Waste Dose $(P)$ with four levels, namely: $p_{0}=$ Control, $p_{1}=$ $2000 \mathrm{ml} /$ plant, $p_{2}=3000 \mathrm{ml} /$ plant, and $p_{3}=4000 \mathrm{ml} /$ plant. The second treatment factor is the Boiler Ash Dose of Palm Oil Mill (K) with four levels, namely: $k_{0}=$ Control, $k_{1}=10 \mathrm{~g} /$ plant, $k_{2}=20 \mathrm{~g} /$ plant, and $k_{3}=30 \mathrm{~g} /$ plant . The results showed that there was no interaction between the various doses of liquid waste and ash of the palm oil mill boiler on the growth of oil palm seedlings. The independent effect of a $4000 \mathrm{ml}$ palm oil mill effluent / plant can provide the highest average in the observation parameters of leaf area, and canopy dry weight. The treatment of 30 grams of palm oil boiler ash ash / plant had a significantly different effect on plant height at 90 DAC, leaf area, canopy dry weight.

Keywords : boiler ash, palm oil, liquid waste, palm oil mill.

\section{PENDAHULUAN}

Kelapa sawit (Elaeis guineensis Jacq.) merupakan salah satu tanaman perkebunan yang mempunyai peranan penting bagi subsektor perkebunan. Kebutuhan minyak kelapa sawit terus meningkat sejalan dengan peningkatan jumlah penduduk dunia, yang juga di pacu dengan ditemukannya teknologi pengolahan atau diversifikasi industri. Hal ini menunjukan bahwa peluang pasar kelapa sawit sangat baik sehingga produksi kelapa sawit mempunyai prospek untuk dikembangkan di Indonesia (Dradjat, 2008).

Kebutuhan minyak kelapa sawit ini juga diiringi dengan pertambahan luas areal perkebunan kelapa sawit. Luas aeal perkebunan kelapa sawit di Indonesia terus bertambah dengan pesat, pada tahun 2014 luas areal perkebunan 10,96 juta ha dan di perkirakan pada tahun 2015 meningkat 4,46\% menjadi 11,44 juta ha (Badan Pusat Statistik, 2017). Kelapa sawit memberikan persentase hasil tertinggi perhektarnya dibandingkan dengan tanaman penghasil minyak lainnya saat ini (Corley dan Tinker, 2003).

Pada pengembangan kelapa sawit, bibit merupakan produk dari suatu proses pengadaan tanaman yang dapat berpengaruh terhadap pencapaian produksi 
dan kesinambungan usaha perkebunan (Syakir et al, 2010). Pada umumnya pembibitan kelapa sawit yang dilakukan melalui dua tahap (double stage nursery). Tahap pertama yaitu tahap pembibitan awal (prenursery) pada tahap ini kecambah ditanam dalam polybag berukuran kecil sampai bibit berumur 3-4 bulan dan dilanjutkan dengan tahap kedua pembibitan utama (main nursery) menggunakan polybag ukuran besar sampai bibit berumur 10-14 bulan (Sharma, 2013).

Pertumbuhan bibit kelapa sawit yang berkualitas, sangat diperlukan pemupukan, hal ini berhubungan bibit kelapa sawit memiliki pertumbuhan yang sangat cepat sehingga membutuhkan hara yang cukup (Gusniwati et al., 2012). Pemupukan perlu dilakukan secara efisien dan efektif, jika tanaman kelapa sawit kelebihan dosis pupuk maka tanaman kelapa sawit akan keracunan, jika kekurangan maka tanaman kelapa sawit akan mengalami kekurangan unsur hara yang menyebabkan pertumbuhan terhambat dan penurunan produksi (Hartono et al., 2014).

Limbah Cair Pabrik Kelapa Sawit (LCPKS) merupakan salah satu bahan organik yang mengandung unsur hara cukup tinggi seperti $\mathrm{N}$ (Nitrogen), $\mathrm{P}$ (fosfor), K (Kalium), Mg (Magnesium) dan Ca (Kalsium). Limbah cair pabrik kelapa sawit berpeluang besar untuk digunakan sebagai sumber hara bagi tanaman kelapa sawit disamping memberikan kelembaban tanah. Pemberian LCPKS dapat memperbaiki sifat fisik, kimia dan biologi tanah serta dapat meningkatkan status hara tanah. Sementara ditinjau dari kandungan haranya, setiap satu ton limbah cair pabrik kelapa sawit mengandung hara setara dengan 1,56 kg Urea, 0,25 kg TSP, 2,50 kg MOP dan $1 \mathrm{~kg}$ Kiserit (Putri, 2011).

Hasil penelitian Fiman k, $d k k$ (2014) penambahan limbah cair pada bibit kelapa sawit sama pada taraf tertinggi $3000 \mathrm{ml} /$ tanaman masih terus menunjukan peningkatan bobot basah tajuk dan akar masih akan terus bertambah jika limbah cair pabrik kelapa sawit diberikan dengan volume yang lebih besar. Aplikasi limbah cair pabrik kelapa sawit secara nyata dapat memperbaiki kesuburan tanah terutama sifat kimia tanah, seperti hasil penelitian Ermadani dan Arsyad (2007) dimana aplikasi limbah cair pabrik kelapa sawit dapat memperbaiki beberapa sifat kimia tanah air, menaikan pH, C-organik, N-total, P-tersedia, KTK, K-dd, Ca-dd, dan peningkatan Mg-dd. Hasil penelitian Rinaldi dkk., (2010) menyatakan bahwa 
pemberian limbah cair kelapa sawit dengan dosis 1,6 1/polybag (40x35) cm memberikan pengaruh terbaik terhadap luas daun total, bobot kering pupus bibit kakao dan diameter bibit kakao di polybag.

Abu boiler merupakan bahan amlioran, yang mana bahan ini dikenal baik sebagai bahan yang dapat memperbaiki sifat fisik dan kimia tanah. Abu boiler dapat digunakan untuk menetralkan tanah masam dan meningkatkan kandungan hara tanah. Abu boiler adalah limbah padat pabrik kelapa sawit hasil dari sisa pembakaran cangkang dan serat di dalam mesin boiler. Menurut Amaru (2008) abu boiler mengandung unsur hara yang sangat bermanfaat dan dapat diaplikasikan pada tanaman sawit sebagai pupuk tambahan atau pengganti pupuk

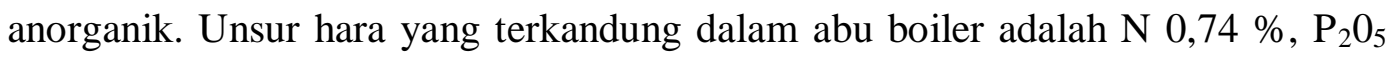
$0,84 \%, \mathrm{~K}_{2} 0$ 2,07 \%, Mg 0,62 \%. Menurut Ricki $d k k$, (2013) abu boiler memiliki kandungan 30-40 \% $\mathrm{K}_{2} 0,7 \% \mathrm{P}_{2} 0_{5}, 9 \% \mathrm{CaO}$ dan $3 \% \mathrm{MgO}$. Abu cenderung meningkatkan jumlah unsur hara $\mathrm{P}, \mathrm{K}, \mathrm{Ca}$, dan $\mathrm{Mg}$ serta meningkatkan unsur hara $\mathrm{N}$ bagi tanaman.

Pinta (2009) yang menyatakan bahwa pemberian abu boiler dan tanda kosong kelapa sawit dengan dosis $120 \mathrm{~kg} / \mathrm{ha}$ dapat meningkatkan pertumbuhan dan produksi kacang tanah. Astianto (2013), juga menambahkan bahwa pemberian abu cangkang buah kelapa sawit dengan dosis $29 \mathrm{~g}$ per polybag memberikan pengaruh terhadap peningkatan pertumbuhan bibit kelapa sawit di pembibitan utama. Josh (2013) juga menyatakan bahwa penggunaan abu boiler cangkang kelapa sawit pada dosis $600 \mathrm{~g} / \mathrm{plot}$ memberikan produksi tertinggi pada tanaman selada di tanah Inceptisol.

Maksud dilakukan penelitian ini adalah untuk mempelajari pengaruh dosis limbah cair dan abu boiler pabrik kelapa sawit terhadap pertumbuhan bibit kelapa sawit di prenursery. Tujuan penelitian untuk mengetahui pengaruh dosis limbah cair dan abu boiler pabrik kelapa sawit manakah yang memberikan nilai tertinggi terhadap pertumbuhan bibit kelapa sawit di prenursery.

\section{METODE PENELITIAN}

Penelitian telah dilaksanakan Kampung Sukaraja Desa Jatisari Kecamatan Karangpawitan Kabupaten Garut dengan ketinggian 715 m diatas permukaan laut. 
Tipe curah hujan berdasarkan kriteria Schmidt dan Ferguson (1951) adalah tipe curah hujan C, Data curah hujan selama 10 tahun terdapat pada. Penelitian akan dilaksanakan dari bulan September sampai Desember 2019.

Bahan-bahan yang digunakan dalam Penelitian ini adalah tanah bagian atas (topsoil) yang sudah diayak (Data analisis tanah pada lampiran 2), kecambah kelapa sawit varietas D x P (deskripsi pada lampiran 3), limbah cair pabrik kelapa sawit yang terdapat pada bak ke 6 , abu boiler pabrik kelapa sawit, polybag ukuran $20 \mathrm{~cm} \times 20 \mathrm{~cm}$, bambu, naungan, dan pestisida. Alat-alat yang digunakan meliputi cangkul, penyaring (ayakkan) golok, handsprayer, sigmat digital, meteran/penggaris, timbangan, ajir, papan nama, alat-alat tulis dan kamera.

\section{HASIL DAN PEMBAHASAN}

\section{Tinggi Bibit (cm)}

Rata-rata tinggi bibit dapat dilihat pada Tabel 1. Hasil analisis ragam menunjukkan tidak terjadi interaksi antara berbagai dosis limbah cair pabrik kelapa sawit dan dosis abu boiler pabrik kelapa sawit terhadap rata-rata tinggi bibit pada semua umur pengamatan.

Tabel 1. Pengaruh Dosis Limbah Cair dan Abu Boiler Pabrik Kelapa Sawit Terhadap Rata-rata Tinggi Bibit Pada Umur 30 - 90 HST

\begin{tabular}{|c|c|c|c|}
\hline Perlakuan & $\begin{array}{c}\text { Tinggi Bibit } \\
(\mathrm{cm}) \\
30 \mathrm{HST}\end{array}$ & $\begin{array}{c}\text { Tinggi Bibit } \\
(\mathrm{cm}) \\
60 \mathrm{HST}\end{array}$ & $\begin{array}{c}\text { Tinggi Bibit } \\
(\mathrm{cm}) \\
90 \mathrm{HST}\end{array}$ \\
\hline \multicolumn{4}{|l|}{ Dosis Limbah Cair (P) } \\
\hline $\mathrm{p}_{0}$ (kontrol) & $1,95 \mathrm{a}$ & $3,36 \mathrm{a}$ & $7,07 \mathrm{a}$ \\
\hline $\mathrm{p}_{1}(2000 \mathrm{ml} / \mathrm{tanaman})$ & $1,76 \mathrm{a}$ & $3,41 \mathrm{a}$ & $6,84 \mathrm{a}$ \\
\hline $\mathrm{p}_{2}(3000 \mathrm{ml} /$ tanaman $)$ & $1,69 \mathrm{a}$ & $3,20 \mathrm{a}$ & $7,15 \mathrm{a}$ \\
\hline $\mathrm{p}_{3}(4000 \mathrm{ml} /$ tanaman $)$ & $1,78 \mathrm{a}$ & $3,46 \mathrm{a}$ & $8,05 \mathrm{a}$ \\
\hline \multicolumn{4}{|l|}{ Dosis Abu Boiler $(\mathrm{K})$} \\
\hline $\mathrm{k}_{0}($ kontrol $)$ & $1,51 \mathrm{a}$ & $2,77 \mathrm{a}$ & $6,49 \mathrm{a}$ \\
\hline $\mathrm{k}_{1}(10 \mathrm{~g} /$ tanaman $)$ & $1,69 \mathrm{a}$ & $3,32 \mathrm{a}$ & $7,25 \mathrm{a}$ \\
\hline $\mathrm{k}_{2}(20 \mathrm{~g} /$ tanaman $)$ & $2,14 \mathrm{a}$ & $3,78 \mathrm{a}$ & $7,06 \mathrm{a}$ \\
\hline $\mathrm{k}_{3}(30 \mathrm{~g} /$ tanaman $)$ & $1,84 \mathrm{a}$ & $3,56 \mathrm{a}$ & $8,31 \mathrm{~b}$ \\
\hline
\end{tabular}


Hasil analisis ragam menunjukkan semua dosis limbah cair yang diberikan pada usia tanaman 30 HST, 60 HST, dan 90 HST tidak berbeda nyata pada tinggi Bibit. Pada taraf perlakuan dosis limbah cair pada semua taraf perlakuan. Tinggi Bibit dipengaruhi unsur hara nitrogen yang tersedia. Nitrogen merupakan unsur hara penting yang diperlukan pada fase vegetatif tanaman. Dari hasil analisis tanah dan pupuk menunjukan ketersediaan nitrogen yang rendah, sehingga unsur hara nitrogen kurang berperan dalam meningkatkan laju fotosintesis, jika fotosintesis meningkat maka laju maka pertambahan tinggi bibit juga meningkat. Ardiana et al., (2016) menyatakan bahwa nitrogen berperan dalam pembentukan sel-sel klorofil dimana klorofil berguna dalam fotosintesis sehingga dibentuk energi yang diperlukan sel untuk aktivitas pembelahan, pembesaran dan pemanjangan.

Hasil analisis ragam menunjukkan berbeda nyata antara taraf perlakuan $\mathrm{k}_{0}$, $\mathrm{k}_{1}, \mathrm{k}_{2}$, dibanding taraf perlakuan $\mathrm{k}_{3}$ pada usia tanaman $90 \mathrm{HST}$. Hal ini diduga karena reaksi positif dari pemberian abu yang mampu meningkatkan $\mathrm{pH}$ tanah. $\mathrm{pH}$ tanah mempengaruhi mudah tidaknya unsur hara baik makro maupun mikro diserap oleh akar tanaman. Harjadi (1991), menyatakan bahwa tanaman akan tumbuh dengan baik apabila unsur hara yang dibutuhkan cukup tersedia dalam bentuk yang dapat diserap oleh tanaman. Menurut Marsono dan Sigit (2001), unsur fosfor merupakan komponen utama asam nukleat yang berperan dalam pembelahan sel pada titik tumbuh sehingga berpengaruh terhadap tinggi bibit.

\section{Diameter Batang (mm)}

Rata-rata diameter batang dapat dilihat pada Tabel 2. Hasil analisis ragam menunjukkan tidak terjadi interaksi antara berbagai dosis limbah cair pabrik kelapa sawit dan dosis abu boiler pabrik kelapa sawit terhadap rata-rata diameter batang pada semua umur pengamatan.

Hasil analisis ragam menunjukkan tidak berbeda nyata antara berbagai taraf perlakuan dan berbagai stadia umur tanaman baik pada 30, 60, dan 90 HST.. Keadaan tanah yang padat diduga kurang maksimal dalam penyerapan unsur hara sehingga pemberiaan limbah cair tidak menunjukan perbedaan. Pertambahan diameter batang dan tinggi bibit biasanya sejalan dengan pertumbuhan tinggi 
bibit. Semakin tinggi suatu tanaman maka diameter batang juga akan semakin lebar. Menurut Lakitan (2000) menyatakan pertambahan tinggi yang dicapai oleh pertumbuhan meristem yang sering disertai dengan panambahan tebal batang atau diameter. Penambahan ini disebabkan oleh pertumbuhan sekunder aktivitas kambium pembuluh yang menambah jaringan pembuluh sehingga menyebabkan pertumbuhan kesamping. Dengan demikian dapat dikatakan bahwa pertumbuhan tinggi bibit sejalan dengan pertambahan diameter batang, dimana semakin tinggi bibit maka pertambahan diameter batangnya pun semakin besar.

Hasil analisis ragam abu boiler pada berbagai stadia umur dan berbagai taraf perlakuan terlihat tidak berbeda nyata. Hal ini diduga faktor yang mempengaruhi pertumbuhan diameter batang tanaman yaitu faktor genetik dan faktor lingkungan. Faktor genetik yang mempengaruhi pertambahan diameter batang yaitu varietas tanaman itu sendiri. Faktor lingkungan yang mempengaruhi pertumbuhan diameter batang yaitu kondisi lingkungan, pencahayaan, suhu serta unsur hara dan ketersediaan air. Menurut lakitan (2000), bahwa faktor lingkungan berpengaruh besar terhadap pemanjangan diameter batang adalah suhu dan cahaya.

Tabel 2. Pengaruh Dosis Limbah Cair dan Abu Boiler Pabrik Kelapa Sawit terhadap Rata-rata Diameter Batang (mm) Pada Umur 30 - 90 HST

\begin{tabular}{|c|c|c|c|}
\hline Perlakuan & $\begin{array}{c}\text { Diameter } \\
\text { Batang (mm) } \\
30 \text { HST }\end{array}$ & $\begin{array}{c}\text { Diameter } \\
\text { Batang }(\mathrm{mm}) \\
60 \mathrm{HST}\end{array}$ & $\begin{array}{c}\text { Diameter } \\
\text { Batang (mm) } \\
90 \mathrm{HST}\end{array}$ \\
\hline \multicolumn{4}{|l|}{ Dosis Limbah Cair $(\mathrm{P})$} \\
\hline $\mathrm{p}_{0}$ (kontrol) & $2,94 \mathrm{a}$ & $3,70 \mathrm{a}$ & $4,33 \mathrm{a}$ \\
\hline $\mathrm{p}_{1}(2000 \mathrm{ml} / \mathrm{tanaman})$ & $2,85 \mathrm{a}$ & $3,61 \mathrm{a}$ & $4,22 \mathrm{a}$ \\
\hline $\mathrm{p}_{2}(3000 \mathrm{ml} / \mathrm{tanaman})$ & $2,86 \mathrm{a}$ & $3,60 \mathrm{a}$ & $4,19 \mathrm{a}$ \\
\hline $\mathrm{p}_{3}(4000 \mathrm{ml} /$ tanaman $)$ & $2,90 \mathrm{a}$ & $3,65 \mathrm{a}$ & $4,26 \mathrm{a}$ \\
\hline \multicolumn{4}{|l|}{ Dosis Abu Boiler $(\mathrm{K})$} \\
\hline $\mathrm{k}_{0}($ kontrol $)$ & $2,85 \mathrm{a}$ & $3,59 \mathrm{a}$ & $4,20 \mathrm{a}$ \\
\hline $\mathrm{k}_{1}(10 \mathrm{~g} /$ tanaman $)$ & $2,88 \mathrm{a}$ & $3,64 \mathrm{a}$ & $4,25 \mathrm{a}$ \\
\hline $\mathrm{k}_{2}(20 \mathrm{~g} /$ tanaman $)$ & $2,97 \mathrm{a}$ & $3,73 \mathrm{a}$ & $4,37 \mathrm{a}$ \\
\hline $\mathrm{k}_{3}(30 \mathrm{~g} /$ tanaman $)$ & $2,85 \mathrm{a}$ & $3,59 \mathrm{a}$ & $4,18 \mathrm{a}$ \\
\hline $\begin{array}{ll}\text { Keterangan } & \text { Angk } \\
& \text { menu } \\
& \text { Dunc }\end{array}$ & $\begin{array}{l}\text { yang dita } \\
\mathrm{k} \text { berbeda } \\
5 \% \text {. }\end{array}$ & $\begin{array}{l}\text { engan } h \\
\text { nenurut }\end{array}$ & $\begin{array}{l}\mathrm{f} \quad \text { yang sam } \\
\text { Jarak }\end{array}$ \\
\hline
\end{tabular}




\section{Panjang Akar (cm)}

Rata-rata panjang akar dapat dilihat pada Tabel 3. Hasil analisis ragam menunjukkan tidak terjadi interaksi antara berbagai dosis limbah cair pabrik kelapa sawit dan dosis abu boiler pabrik kelapa sawit terhadap rata-rata panjang akar.

Secara mandiri hasil analisis ragam menunujukkan tidak berbeda nyata pada parameter panjang akar pada berbagai taraf perlakuan baik pada perlakuan limbah cair maupun abu boiler. Berdasarkan hasil analisis tanah pada lampiran 2 Unsur hara $\mathrm{P}$ yang terkandung pada tanah diduga sudah mencukupi kebutuhan pertumbuhan pada tanaman. Peran utama $\mathrm{P}$ adalah membantu perkembangan tanaman khususnya akar tanaman. Sutedjo dan Kartasapotera (1988), menyatakan unsur phospat berperan menggiatkan pertumbuhan jaringan tanaman pada titik tumbuh seperti pada ujung batang dan ujung akar. Menurut Brady (1982), perbaikan sifat kimia tanah terjadi berkat penambahan pupuk organik antara lain memperbesar tukar kation tanah, meningkatkan kelarutan unsur fosfat dalam tanah, dan menyediakan unsur hara. Pupuk organik juga memperbaiki kondisi biologi tanah selain sifat fisika, kimia, bahkan secara tidak langsung kondisi fisika dan kimia tanah dipengaruhi oleh adanya aktivitas mikroorganisme.

Tabel 3. Pengaruh Dosis Limbah Cair dan Abu Boiler Pabrik Kelapa Sawit Terhadap Rata-rata Panjang Akar (cm) Pada Umur 90 HST

\begin{tabular}{lc}
\hline \multicolumn{1}{c}{ Perlakuan } & Panjang Akar $(\mathrm{cm})$ \\
\hline Dosis Limbah Cair $(\mathrm{P})$ & $18,36 \mathrm{a}$ \\
$\mathrm{p}_{0}$ (kontrol) & $17,00 \mathrm{a}$ \\
$\mathrm{p}_{1}(2000 \mathrm{ml} /$ tanaman $)$ & $18,15 \mathrm{a}$ \\
$\mathrm{p}_{2}(3000 \mathrm{ml} /$ tanaman $)$ & $20,14 \mathrm{a}$ \\
$\mathrm{p}_{3}(4000 \mathrm{ml} /$ tanaman $)$ & $18,07 \mathrm{a}$ \\
\hline Dosis Abu Boiler $(\mathrm{K})$ & $17,10 \mathrm{a}$ \\
$\mathrm{k}_{0}($ kontrol $)$ & $21,31 \mathrm{a}$ \\
$\mathrm{k}_{1}(10 \mathrm{~g} / \mathrm{tanaman})$ & $17,17 \mathrm{a}$ \\
$\mathrm{k}_{2}(20 \mathrm{~g} / \mathrm{tanaman})$ & dengan huruf yang sama \\
$\mathrm{k}_{3}(30 \mathrm{~g} / \mathrm{tanaman})$ & \\
Keterangan : Angka rata-rata yang ditandai &
\end{tabular}




\section{Nisbah Pupus Akar (g/g)}

Rata-rata nisbah pupus akar dapat dilihat pada Tabel 4. Hasil analisis ragam menunjukkan tidak terjadi interaksi antara berbagai dosis limbah cair pabrik kelapa sawit dan dosis abu boiler pabrik kelapa sawit terhadap rata-rata nisbah pupus akar.

Tabel 4. Pengaruh Dosis Limbah Cair dan Abu Boiler Pabrik Kelapa Sawit Terhadap Rata-rata Nisbah Pupus Akar Pada Umur 90 HST

\begin{tabular}{|c|c|}
\hline Perlakuan & Nisbah Pupus Akar g/g \\
\hline \multicolumn{2}{|l|}{ Dosis Limbah Cair (P) } \\
\hline $\mathrm{p}_{0}($ kontrol $)$ & $4,42 \mathrm{a}$ \\
\hline $\mathrm{p}_{1}(2000 \mathrm{ml} /$ tanaman $)$ & $4,71 \mathrm{a}$ \\
\hline $\mathrm{p}_{2}(3000 \mathrm{ml} /$ tanaman $)$ & $4,63 \mathrm{a}$ \\
\hline $\mathrm{p}_{3}(4000 \mathrm{ml} /$ tanaman $)$ & $5,20 \mathrm{a}$ \\
\hline \multicolumn{2}{|l|}{ Dosis Abu Boiler (K) } \\
\hline $\mathrm{k}_{0}($ kontrol $)$ & $4,83 \mathrm{a}$ \\
\hline $\mathrm{k}_{1}(10 \mathrm{~g} /$ tanaman $)$ & $4,26 \mathrm{a}$ \\
\hline $\mathrm{k}_{2}(20 \mathrm{~g} /$ tanaman $)$ & $4,19 \mathrm{a}$ \\
\hline $\mathrm{k}_{3}(30 \mathrm{~g} / \mathrm{tanaman})$ & $5,68 \mathrm{a}$ \\
\hline $\begin{array}{ll}\text { Keterangan : } & \text { Angka } \\
& \text { menunj } \\
& \text { Duncar }\end{array}$ & $\begin{array}{l}\text { ndai dengan huruf yang sama } \\
\text { nyata menurut Uji Jarak Berganda }\end{array}$ \\
\hline
\end{tabular}

Hasil analisis ragam menunjukkan tidak berbeda nyata pada semua taraf perlakuan baik perlakuan limbah cair maupun abu boiler. Berdasarkan hasil penelitian, nilai nisbah pupus akar berkisar antara 4,19-5,68. Nisbah pupus akar yang bernilai lebih dari satu menunjukkan pertumbuhan tanaman lebih ke arah pupus, sedangkan nisbah pupus akar yang bernilai kurang dari satu menunjukan pertumbuhan tanaman lebih ke arah akar Irwan et al., (2017).

Pada saat pembibitan pre nursery diduga tanaman sawit sudah mendapatkan unsur hara yang memadai bagi pertumbuhan Bobot kering ke atas tanaman (tajuk) maupun kebawah (akar) pada berbagai taraf sehingga pada parameter NPA menjadi tidak berbeda nyata. La Salina (2004) mengemukakan bahwa pertumbuhan tanaman maksimal dapat dicapai bila semua kondisi pertumbuhan termasuk penyediaan unsur hara berada dalam jumlah yang cukup dan seimbang dan siap diserap oleh tanaman. 
Rasio tajuk akar merupakan faktor penting dalam pertumbuhan tanaman yang mencerminkan kemampuan dalam penyerapan hara pada tanaman. Hasil bobot kering tajuk dan akar menunjukkan penyerapan air dan hara oleh akar yang ditranslokasikan ke tajuk tanaman. Hal ini sesuai dengan pendapat Sitompul dan Guritno (1995) bahwa pertumbuhan suatu bagian tanaman diikuti dengan pertumbuhan bagian tanaman lainnya. Bobot tajuk yang meningkat diikuti dengan peningkatan Bobot akar.

\section{KESIMPULAN}

Berdasarkan hasil penelitian dapat ditarik kesimpulan sebagai berikut :

1. Tidak terjadi interaksi antara berbagai dosis limbah cair dan abu boiler pabrik kelapa sawit terhadap pertumbuhan bibit kelapa sawit.

2. Pengaruh mandiri dosis limbah cair pabrik kelapa sawit $4000 \mathrm{ml} /$ tanaman dapat memberikan rata-rata tertinggi pada parameter pengamatan luas daun, dan berat kering tajuk. Perlakuan dosis abu boiler kelapa sawit 30 gram/tanaman memberikan pengaruh yang berbeda nyata pada Tinggi Bibit umur 90 HST, luas daun, berat kering tajuk.

\section{DAFTAR PUSTAKA}

Amaru, K. 2008. Limbah Industri Kelapa Sawit. www.geocities.com/kharistya_amaru/blog.limbah $\quad$-sawit.html-85k-. Diakses pada November 2019.

Ardiana, R. S., Anom, E., dan Armaini. (2016). Aplikasi Solid Pada Medium Bibit Kelapa Sawit (Elaeis Guineensis Jacq .) Di Main Nursery. Jom Faperta, 3(1), 12-16.

Astianto A. 2013. Pemberian berbagai Dosis Abu Boiler pada Pembibitan Kelapa Sawit (Elaeis guineensis Jacq.) di Pembibitan Utama (Main Nursery). Skripsi Fakultas Pertanian Universitas Riau, Pekanbaru. (Tidak dipublikasikan).

Badan Pusat Stastistik. 2017. Statistik Kelapa Sawit 2007. In Katalog (Pp. 1-100).

Corley, R.V.H. dan P.B. Tinker. 2003. The Oil Palm (Fourth edition). Blackwell Science Ltd. Main Street Malden. USA.

Dradjat, B. 2008. Prospek Kebun Sawit Masih Cerah. Lembaga Riset Perkebunan Indonesia. Jakarta. 
Ermadani dan A.R. Arsyad 2007. Perbaikan Beberapa Sifat Kimia Tanah Mineral Masam dengan Pemanfaatan Limbah Cair Pabrik Kelapa Sawit. Jurnal Penelitian Universitas Jambi, Seri Sains.

Gomez, K., dan Gomez, A. 2010. Prosedur Statistik untuk Penelitian Pertanian. UI-Press. Jakarta.

Gusniwati, H. Salim, dan J. Mandasari. 2012. Kelapa Sawit (Elaeis guineensis Jacq) di pembibitan utama dengan perbedaan kombinasi pupuk cair nutrifarm dan NPKmg. Jurnal Pertanian, Vol.1

Harjadi, S. S. (1991). Pengantar Agronomi. PT. Gramedia. Jakarta.

Hartono, B., Adwirman, dan G.M.E. Manurung. 2014. The young oil palm (Elaeis guineensis Jacq) cultivation technique in tidal lands made by farmers in district of Bangko Pusako Rokan Hilir. Jurusan Agroteknologi, Fakultas Pertanian UNRI. Riau. Jom Faperta 1 (2)/

Josh, D. 2013. Pertumbuhan dan Produksi selada (Lactuca sativa) pada tanah Inceptisol dengan aplikasi abu cangkang kelapa sawit. Skripsi Fakultas Pertanian Riau. Pekanbaru.

Lakitan. B. 2000. Fisiologi Tumbuhan dan Perkembangan Tanaman. Raja wali Press. Jakarta

Marsono dan P. Sigit, 2001. Jenis Pupuk dan Aplikasinya. Penebar Swadaya. Jakarta.

Pinta, P. H. (2009) Pengaruh Pemberian Abu Janjang Kelapa Sawit terhadap Pertumbuhan dan Produksi Kacang Tanah (Arachis hypogeae L ). Skripsi, Fakultas Pertanian Riau, Pekanbaru.

Putri, R.E.2011. Pengaruh Pemberian Bahan Organik Limbah Cair Kelapa Sawit terhadap Beberapa Sifat Tanah Oxisol dan Pertumbuhan Tanaman Kedelai (Glicine max (L) Merril). Skripsi. Universitas Andalas. Padang.

Rinaldi, Hanibal, dan S Wira 2010. Pengaruh Limbah Cair Pabrik Kelapa Sawit Terhadap Pertumbuhan Bibit Kakao (Theobroma cacao, L) Fakultas Pertanian Universitas Jambi.

Sutedjo, Mulyani Mul dan A.G Kartasapoetra. 1988. Pengantar Ilmu Tanah PT. Bina Aksara. Jakarta.

Syakir, M., D. Allorerung, Z. Poeloengan, Syafaruddin, dan W. Rumini. 2010. Budidaya Kelapa Sawit. Pusat Penelitian dan Pengembangan Perkebunan. Aska Media. Bogor 